\title{
Comparing Different Methods of Learning in the Development of Social Accountability and CanMEDS Roles in Medical Students
}

\author{
Alvin H. Ip*, MD', Jerry C. Ku*, MD², Wayne S.W. Hung*, MD², Jane A. Buxton, MBBS ${ }^{4}$ \\ ${ }^{1}$ Division of Physical Medicine \& Rehabilitation, Faculty of Medicine, University of British Columbia, Vancouver, BC \\ ${ }^{2}$ Division of Neurosurgery, Faculty of Medicine, University of Toronto, Toronto, ON \\ ${ }^{3}$ Department of Medicine, Faculty of Medicine, University of British Columbia, Vancouver, BC \\ ${ }^{4}$ School of Population and Public Health, Faculty of Medicine, University of British Columbia, Vancouver, BC \\ * Equal contributions
}

\section{A B STRACT}

Objective: Medical students at the University of British Columbia undertake a population health course that aims to cultivate social accountability and CanMEDS roles. Students choose between Discussion Group Option (DGO), Community Service Learning Option (CSLO), or Self-Directed Project Option (SDPO). The objective of this study was to evaluate the effectiveness of these three different learning options in developing social accountability and CanMEDS roles in medical students.

Methods: Expert consultation and literature review were undertaken to develop a self-report survey. Students who had completed the course from 2009 to 2013 were surveyed. The results were analyzed to evaluate differences between groups.

Results: We recruited 168 participants with equal representation from each option. CSLO and SDPO students reported greater development of social accountability and CanMEDS roles from the course compared to DGO students. In addition, CSLO and SDPO students reported greater academic output and satisfaction from their experience.

Conclusion: Students who participated in community-based or project-based learning reported significantly better acquisition of social accountability and CanMEDS roles compared to students who engaged in group discussion.

\section{RÉ S U M É}

Objectif: Les étudiants en médecine de l'Université de la Colombie-Britannique suivent un cours sur la santé de la population qui vise à cultiver la responsabilité sociale et les rôles CanMEDS. Les étudiants choisissent entre l'option de discussion de groupe (DGO, de l'anglais), l'option d'apprentissage par l'engagement communautaire (CSLO, de l'anglais) ou l'option de projet autonome (SDPO, de l'anglais). L'objectif de cette étude était d'évaluer l'efficacité de ces trois options d'apprentissage différentes pour le développement de la responsabilité sociale et des rôles CanMEDS chez les étudiants en médecine.

Méthodes: Des consultations d'experts et une revue de la littérature ont été entreprises afin de concevoir un sondage d'autodéclaration. Les étudiants ayant complété le cours de 2009 à 2013 ont été interrogés. Les résultats ont été analysés afin d'évaluer les différences entre les groupes.

Résultats: Nous avons recruté 168 participants, avec une représentation égale pour chaque option. Les étudiants des groupes CSLO et SDPO ont déclaré plus de développement de leur sens de responsabilité sociale et des rôles CanMEDS à la suite du cours, en comparaison aux étudiants du groupe DGO. De plus, les étudiants des groupes CSLO et SDPO ont rapporté un plus grand nombre de réalisations scolaires et une meilleure satisfaction par rapport à leur expérience.

Conclusion: Les étudiants qui ont participé à l'apprentissage par l'engagement communautaire ou par l'entremise d'un projet autonome ont rapporté une acquisition nettement meilleure de la responsabilité sociale et des rôles CanMEDS, en comparaison aux étudiants qui ont participé à une discussion de groupe.

\section{INTRODUCTION}

During the first two years of medical school, students at the University of British Columbia (UBC) participate in a longitudinal course known as "Doctor, Patient, and Society" (DPAS). This population health course addresses topics such as the social determinants of health, the patient-doctor relationship, ethics, community and public health, culture, addiction medicine, and health disparities [1]. The aim of the course is to cultivate social accountability and develop intrinsic CanMEDS roles (Scholar, Keywords: Medical students; Learning methods; Learning outcomes
Communicator, Collaborator, Manager, Health Advocate, and Professional) in medical students through core readings, lectures, online modules, seminars, and three different activity options $[2,3]$.

Medical students have different learning styles and one single approach does not work for all students [4]. It has been well demonstrated that self-determination is an effective method of intrinsic motivation, associated with deep learning, better performance, and psychological satisfaction [5-7]. As such, au- 
tonomous support for self-determination is a fundamental aspect of personalized learning that is provided through DPAS. In the second year of the course (DPAS 420), students are able to choose between one of three different activity options to apply their population health expert competencies in a practical manner. Students can participate in the Self-Directed Project Option (SDPO) or the Community Service Learning Option (CSLO) with an application detailing their intended activity and its relevance. Students who do not apply to these options or, in rare instances, are unsuccessful in their applications, participate in the Discussion Group Option (DGO). Medical students participate in their matched options for the entirety of their second year and are required to devote at least 1.5 hours each week to their respective activities. This allows students to choose an option that is most aligned with their learning style and interests.

DGO students meet weekly in small groups to participate in discussions, assignments, and presentations relevant to the course and lecture material. CSLO students partake in experiential learning in the community through volunteering for non-profit healthcare organizations or community initiatives of their own choosing; for example, volunteering at a homeless shelter to serve meals, offer free health services, and provide feedback to the shelter provider. Additionally, CSLO students are required to examine their experiences through reflective journal writing. On the other hand, SDPO students pursue independent projects on a variety of clinical and non-clinical topics with the help of project supervisors. Activities may include conducting a literature review, obtaining ethics approval, recruiting participants, conducting qualitative interviews and data analyses, and disseminating results. Examples of SDPO projects include a recent study of the effects of blue lights in washrooms on injection drug users [8]. These options allow students to have varied experiences to achieve the learning objectives of DPAS 420 and provide a unique opportunity to evaluate how these different methods of learning meet the objectives of the course, including social accountability and intrinsic CanMEDS roles.

Social accountability, as defined by the World Health Organization, is to respond to the health concerns of a community, region, or nation where there exists the mandate to serve [9]. The main features of social accountability are to be aware of the unique health needs, views, and priorities of the community and to engage and respond to them accordingly [10]. At the individual level, social accountability has been used interchangeably with professionalism, which is defined as "the means by which individual doctors fulfill the medical profession's contract with society" $[11,12]$. Evaluating the effectiveness of different learning methods in improving social accountability is the primary outcome of our study.

The 2005 CanMEDS Physician Competency Framework, devel- oped by the Royal College of Physicians and Surgeons of Canada, describes the knowledge, skills, and abilities that physicians need for better patient outcomes [3]. The framework is based on seven roles: The central Medical Expert role, as well as the intrinsic roles of Communicator, Collaborator, Manager, Health Advocate, Scholar, and Professional [3]. These roles were utilized in our study, though we recognize that the CanMEDS roles have since been updated; for instance, the Manager role was recently changed to Leader [13]. We will evaluate how students view their educational experiences and their acquisition of these CanMEDS roles as our secondary outcome. Additionally, we will also assess the inter-group differences in research aptitude, academic output, career trajectory, and perceived value of the course as our tertiary outcomes.

Social accountability and development of CanMEDS roles are key objectives in medical education in Canada [2]. Therefore, this research into evaluating the effectiveness of different learning options on improving social accountability and CanMEDS roles will be valuable to all medical schools in Canada. Furthermore, it may stimulate the creation and development of new learning opportunities in Canadian medical schools for the benefit of students. In our study, we hypothesize that there will be significant differences in outcomes between students in different learning options. We believe that participating in CSLO will lead to greater social accountability and that SDPO students will report greater research aptitudes and greater academic output than students who participated in the other options.

\section{METHODS}

We consulted experts on the topic and performed a literature search on PubMed to identify existing validated measures to assess social accountability in medical students, using the search terms "(social accountability OR social responsibility OR socially accountable OR socially responsible) AND (medical student) AND (scale OR measure OR questionnaire OR form)." We found one validated scale that fit with our aforementioned definition of social accountability: The Medical Student Attitudes Toward the Underserved (MSATU) questionnaire, which consisted of a Likert scale (strongly disagree to strongly agree) and True/False questions that assessed first and fourth year U.S. medical students' attitudes toward caring for the underserved [14]. However, we were unable to use this questionnaire in its validated format as some questions did not apply to the public healthcare system in Canada.

Drawing from the questions of the MSATU questionnaire, we developed a 33-item survey to assess our outcomes of interest. We identified and developed the survey objectives and questions in conjunction with an expert panel consisting of professors and course directors in the Faculty of Medicine at UBC and elsewhere 
in Canada. The survey was piloted to 20 medical students and finalized with their feedback. The survey was placed onto the online platform FluidSurveys, a survey hosting tool within Canada. Approvals from UBC Behavioural Research Ethics and UBC Medicine Research Access Committee were obtained.

An e-mail invitation to participate in the survey was sent to medical students who had completed the DPAS 420 course within the last four years. We utilized the class mailing lists that all UBC medical students are automatically enrolled in upon admission. The undergraduate medical program at UBC employs a distributed campus model, comprised of four geographically distinct sites as described in Table 1. The mailing list employed captured students at all four sites. Overall, there were 1,067 possible candidates. Study participants were offered a chance to win a small reward (\$20 Starbucks gift card) via random lottery.

Following a Likert scoring system (where 1 = strongly disagree, 2 = disagree, 3 = neither disagree nor agree, $4=$ agree, and 5 = strongly agree), participants were asked to evaluate a number of statements regarding the impact of DPAS 420 on their medical education. These statements were categorized into five sections: 1) behaviours and attitudes on social accountability; 2) development of intrinsic CanMEDS roles; 3) perceived value of evidence-based medicine, ethics, and research; 4) impact on career trajectory; and 5) perceived value of DPAS 420. Demographic information and academic output were also collected.

The results were collated and analyzed to assess the differences between the DPAS 420 learning options. We utilized a five-point Likert scale with the visual analog underneath displaying the five points as equidistant to each other. Thus, results were assumed to be interval data and reported as mean scores and standard deviation. ANOVA was first used to screen for differences between the three groups, and individual comparisons between the groups using two-tailed t-tests were performed in order to determine specific differences. Given the multiple comparisons performed, Bonferroni corrections to statistical significance were applied to decrease the likelihood of false positives by dividing the traditional $p$-value of 0.05 by the number of comparisons, in our case three, to yield a more stringent $p$-value of 0.017 . This approach has been utilized elsewhere for similar research $[15,16]$.

\section{RESULTS}

We received a total of 224 survey responses, of which 168 surveys were complete (Table 1 ). Only data from complete responses were considered, which provided an overall response rate of $16 \%$. The response rate was higher for medical students in third and fourth year at $22 \%$ and $23 \%$ respectively, whereas the response rate for residents in post-graduate year 1 and 2 was $9 \%$ and $8 \%$ respectively. Sixty-one percent of respondents were women. There were a similar number of responses from each of the DPAS 420 options and representation was obtained from all distributed sites of UBC Medical School. Table $\mathbf{2}$ shows the mean scores of student self-reported agreement with survey items.

\section{Behaviours and attitudes on social accountability}

Students who participated in all three options agreed that it is important for medical students to be actively engaged in the community. However, CSLO students felt significantly more engaged in the community $(4.1 \pm 1.1)$ than SDPO students $(3.7 \pm 1.0)$ or DGO students $(2.3 \pm 1.1)$. Students of all three options agreed that it is important for medical students to be exposed to new patient populations, but only CSLO students stated that they were exposed to previously unencountered populations through DPAS 420 (4.0 \pm 1.2$)$, while DGO and SDPO received neutral scores (2.9 \pm 1.2 and $3.1 \pm 1.2$, respectively).

\section{Development of intrinsic CanMEDS roles}

In general, students reported neutral to positive effects of their DPAS 420 options on the development of these roles. As a whole, DGO students scored the entire CanMEDS section $2.9 \pm 1.0$, CSLO students $3.8 \pm 1.0$, and SDPO students $3.6 \pm 1.0$, reflecting an overall positive response. DGO students reported significantly lower effects than both CSLO and SDPO students in the areas of communicator, collaborator, manager, health advocate, and professional. SDPO students scored significantly higher in the scholar role $(3.3 \pm 1.1)$ than DGO $(2.6 \pm 1.0)$ students.

Perceived value of evidence-based medicine, ethics, and research

SDPO students were significantly more likely to agree that they had gained an understanding of research methods $(3.5 \pm 1.0)$, were more confident in their research abilities $(3.3 \pm 1.1)$, and were more knowledgeable about research ethics $(3.7 \pm 1.0)$ than both CSLO and DGO students. Nevertheless, all three options were neutral to negative in their interest in conducting research after DPAS 420.

\section{Academic output}

Students who participated in CSLO and SDPO had higher rates of resultant academic output, compared to students in DGO. Approximately one third of CSLO and SDPO students $(34 \%$ and $31 \%$ respectively) reported having presented work done during their DPAS 420 option to platforms such as the UBC Medicine Research Forum, the Canadian Conference on Medical Education, and other conferences. Furthermore, $15 \%$ of CSLO and $17 \%$ of SDPO students published work regarding their DPAS 420 projects in publications such as the UBC Medical Journal, the BC Medical Journal, and other peer-reviewed journals. In contrast, only $7 \%$ of 
Table 1: Descriptive statistics of the survey respondents.

\begin{tabular}{|c|c|c|c|}
\hline Potential participants & Respondents & $\begin{array}{l}\text { Percentage response } \\
\text { rate }\end{array}$ & $\begin{array}{c}\text { Percentage of respon- } \\
\text { dents }\end{array}$ \\
\hline All eligible participants $(n=1067)$ & 168 & $16 \%$ & \\
\hline $\begin{array}{l}\text { 3rd year students, DPAS } 2012-2013(n=289) \\
\text { 4th year students, 2011-2012 }(n=256) \\
\text { Post-graduation year } 1,2010-2011(n=263) \\
\text { Post-graduation year } 2,2009-2010(n=259)\end{array}$ & $\begin{array}{l}64 \\
59 \\
24 \\
21\end{array}$ & $\begin{array}{c}22 \% \\
23 \% \\
9 \% \\
8 \%\end{array}$ & $\begin{array}{l}38 \% \\
35 \% \\
14 \% \\
13 \%\end{array}$ \\
\hline $\begin{array}{l}\text { Males } \\
\text { Females }\end{array}$ & $\begin{array}{c}66 \\
102\end{array}$ & & $\begin{array}{l}39 \% \\
61 \%\end{array}$ \\
\hline $\begin{array}{l}\text { Vancouver-Fraser Medical Program }(n=777) \\
\text { Island Medical Program }(n=128) \\
\text { Northern Medical Program }(n=131) \\
\text { Southern Medical Program* }(n=31)\end{array}$ & $\begin{array}{c}135 \\
19 \\
10 \\
4\end{array}$ & $\begin{array}{c}17 \% \\
15 \% \\
8 \% \\
13 \%\end{array}$ & $\begin{array}{c}80 \% \\
11 \% \\
2 \% \\
6 \%\end{array}$ \\
\hline
\end{tabular}

*DPAS 420 in Southern Medical program began in 2012.

Table 2: Mean values of DGO, CSLO, and SDPO student self-reported agreement with five-point Likert survey questions regarding perceptions and outcomes of DPAS 420.

\begin{tabular}{|c|c|c|c|}
\hline Question & $\begin{array}{l}\text { DGO } \\
(n=55)\end{array}$ & $\begin{array}{l}\text { CSLO } \\
(n=59)\end{array}$ & $\begin{array}{l}\text { SDPO } \\
(n=54)\end{array}$ \\
\hline 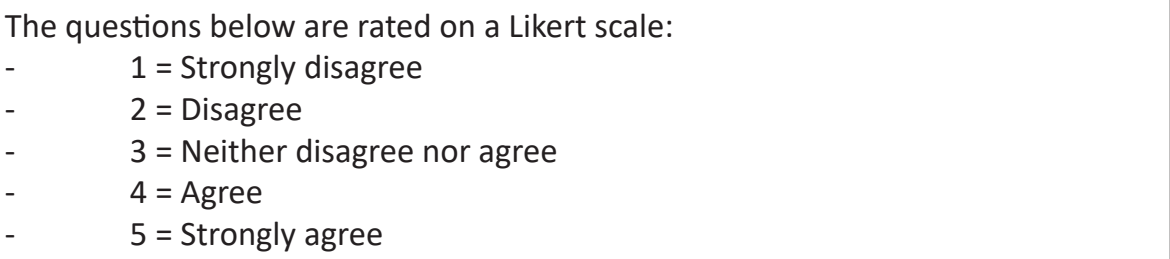 & \multicolumn{3}{|c|}{$\begin{array}{c}\text { Using the scale, Likert responses were totaled } \\
\text { with the data presented as mean } \pm \text { standard } \\
\text { deviation }\end{array}$} \\
\hline \multicolumn{4}{|c|}{ Behaviours and Attitudes on Social Accountability } \\
\hline 11. I felt more actively engaged in the community due to my DPAS 420 Option. & $2.3 \pm 1.0^{*}$ & $4.1 \pm 0.8^{*}$ & $3.7 \pm 1.0^{*}$ \\
\hline $\begin{array}{l}\text { 12. I continued my involvement in the organization/project after DPAS } 420 \text { CSLO } \\
\text { or SDPO. }\end{array}$ & - & $2.5 \pm 1.4$ & $2.9 \pm 1.5$ \\
\hline $\begin{array}{l}\text { 13. My involvement in my DPAS } 420 \text { Option led to other involvements in the same } \\
\text { subject or field of interest. }\end{array}$ & $2.0 \pm 0.9 * *$ & $3.1 \pm 1.1$ & $3.0 \pm 1.3$ \\
\hline $\begin{array}{l}\text { 14. Through my DPAS } 420 \text { Option, I was exposed to previously unencountered } \\
\text { patient populations. }\end{array}$ & $2.9 \pm 1.2$ & $4.0 \pm 1.2 * *$ & $3.1 \pm 1.2$ \\
\hline $\begin{array}{l}\text { 15. It is important for a medical student to be exposed to new patient popula- } \\
\text { tions. }\end{array}$ & $4.6 \pm 0.6$ & $4.8 \pm 0.4^{* *}$ & $4.5 \pm 0.7$ \\
\hline 16. It is important for a medical student to be actively engaged in the community. & $4.1 \pm 0.8^{*}$ & $4.5 \pm 0.5^{*}$ & $4.3 \pm 0.8$ \\
\hline
\end{tabular}


Table 2 (Cont.): Mean values of DGO, CSLO, and SDPO student self-reported agreement with five-point Likert survey questions regarding perceptions and outcomes of DPAS 420.

\begin{tabular}{|l|c|c|c|}
\hline \multicolumn{4}{|c|}{ Development of CanMEDS Roles } \\
\hline 28. My work in my DPAS 420 Option helped to make me a better scholar. & $2.6 \pm 1.0 *$ & $2.9 \pm 1.0$ & $3.3 \pm 1.1 *$ \\
\hline 29. My work in my DPAS 420 Option helped to make me a better communicator. & $2.9 \pm 1.0^{* *}$ & $3.9 \pm 1.0$ & $3.7 \pm 1.0$ \\
\hline 30. My work in my DPAS 420 Option helped to make me a better collaborator. & $2.9 \pm 1.0 * *$ & $4.1 \pm 0.9$ & $3.8 \pm 1.0$ \\
\hline 31. My work in my DPAS 420 Option helped to make me a better manager. & $2.7 \pm 1.0 * *$ & $3.7 \pm 0.9$ & $3.6 \pm 1.0$ \\
\hline 32. My work in my DPAS 420 Option helped to make me a better health advocate. & $3.0 \pm 1.0 * *$ & $4.2 \pm 0.8$ & $3.8 \pm 1.1$ \\
\hline $\begin{array}{l}\text { 33. My work in my DPAS 420 Option helped to make me a better health profes- } \\
\text { sional. }\end{array}$ & $3.1 \pm 0.9 * *$ & $3.8 \pm 0.8$ & $3.6 \pm 1.0$ \\
\hline
\end{tabular}

\section{Understanding of Evidence-Based Medicine, Ethics, and Research}

\begin{tabular}{|c|c|c|c|}
\hline 4. DPAS 420 Option helped me gain an understanding of research methods. & $2.7 \pm 1.0$ & $2.7 \pm 1.0$ & $3.5 \pm 1.0 * *$ \\
\hline 5. I am more confident in my ability to conduct research after DPAS 420 Option. & $2.4 \pm 1.0$ & $2.6 \pm 0.9$ & $3.3 \pm 1.1 * *$ \\
\hline 6. I am more interested in conducting research after DPAS 420 Option. & $2.2 \pm 0.9 * *$ & $2.8 \pm 1.1$ & $3.0 \pm 0.9$ \\
\hline $\begin{array}{l}\text { 7. DPAS } 420 \text { Option helped me gain an understanding of evidence-based medi- } \\
\text { cine. }\end{array}$ & $3.2 \pm 0.9 *$ & $2.7 \pm 1.1^{*}$ & $3.1 \pm 1.0$ \\
\hline 8. DPAS 420 Option helped me gain an understanding of research ethics. & $2.8 \pm 1.0$ & $3.0 \pm 1.1$ & $3.7 \pm 1.0 * *$ \\
\hline
\end{tabular}

\section{Academic Output}

2. I presented my work.

3. I published my work.

\section{Impact on Career Trajectory}

9. By doing my DPAS 420 Option, I discovered a new topic of interest.

10. My work in DPAS 420 Option was a factor in my choice of career/specialty.

27. My work in DPAS 420 Option changed my choice of career/specialty.

\section{Perceived Value of DPAS 420}

\begin{tabular}{|c|c|c|c|}
\hline 20. I am satisfied with the outcome of my DPAS 420 Option. & $3.1 \pm 1.2 * *$ & $4.0 \pm 1.0$ & $4.1 \pm 1.0$ \\
\hline 21. By choosing my DPAS 420 Option, I was able to make good use of my time. & $3.1 \pm 1.5^{* *}$ & $3.9 \pm 1.1$ & $4.0 \pm 1.2$ \\
\hline 22. I enjoyed my experience in my DPAS 420 Option. & $3.1 \pm 1.2 * *$ & $4.3 \pm 0.8$ & $4.1 \pm 1.1$ \\
\hline 23. I valued my experience in my DPAS 420 Option. & $2.9 \pm 1.1 * *$ & $4.2 \pm 1.0$ & $4.1 \pm 1.1$ \\
\hline 24. I was provided adequate support in my DPAS 420 Option. & $3.5 \pm 1.1^{*}$ & $4.1 \pm 0.9 *$ & $3.9 \pm 1.0$ \\
\hline $\begin{array}{l}\text { 25. Overall, my DPAS } 420 \text { Option was an important experience in my medical } \\
\text { education. }\end{array}$ & $2.7 \pm 1.1^{* *}$ & $3.8 \pm 1.0$ & $3.8 \pm 1.2$ \\
\hline $\begin{array}{l}\text { 26. If DPAS } 420 \text { CSLO or SDPO was not available, I would not have been able to } \\
\text { pursue my project }\end{array}$ & $2.6 \pm 0.7^{* *}$ & $3.6 \pm 1.2$ & $3.9 \pm 1.2$ \\
\hline
\end{tabular}

Note: ${ }^{* *}$ denotes significant difference compared to the other two groups, where $p<0.017$.

* denotes significant differences between the indicated groups, where $p<0.017$. 
DGO students were able to present their work, and $4 \%$ of DGO students reported having published their work.

\section{Impact on career trajectory}

DGO students disagreed significantly $(2.3 \pm 0.9)$ while CSLO and SDPO students felt more positive $(3.6 \pm 1.1$ and $3.5 \pm 1.1)$ that DPAS 420 helped them discover a new topic of interest. All three options disagreed that their work in DPAS 420 was a factor in their choice of career or specialty.

Perceived value of DPAS 420

DGO students regarded their DPAS 420 experiences significantly less favourably than CSLO and SDPO students. DGO students (2.7 \pm 1.1 ) disagreed that the option was an important experience in their education compared to CSLO $(3.8 \pm 1.0)$ and SDPO students $(3.8 \pm 1.2)$ who valued their option significantly more positively. CSLO (3.6 \pm 1.2$)$ and SDPO students $(3.9 \pm 1.2)$ also felt that their option enabled them to pursue a project that otherwise would have been unavailable (DGO $2.6 \pm 0.7$ ).

\section{DISCUSSION}

\section{Behaviours and attitudes on social accountability}

As hypothesized, SDPO and CSLO students reported higher ratings of social accountability, consistent with prior studies done regarding the effects of community service learning. Participation of medical students in a summer internship of community service learning was shown to improve attitudes and learning about appropriate professional conduct, topics which the students did not learn or expect to learn in their medical school curriculum [17].

However, CSLO and SDPO students largely disagreed in having continued their community or project involvement after DPAS 420. We suggest that it is important to identify and address the barriers that students face in continuing their activities. For example, as students move onto their third year of undergraduate medical training consisting of heavy clinical duties, protected time for community service or scholarly project interests may be beneficial. This would allow students to continue with these activities that improve their behaviors and attitudes towards social accountability. It is important for medical schools to provide students with opportunities for community service learning throughout the entire curriculum in order to foster the development of social accountability, a core value of medical education. This may also help to offset the decline of empathy reported to occur as students progress through medical school [18].

\section{Development of intrinsic CanMEDS roles}

While students who had chosen and participated in CSLO and SDPO options reported improvements on their intrinsic CanMEDS competencies, DGO students did not, although we had expected involvement in discussions groups would help students become better communicators. It is possible that students may not see speaking to each other as an effective way to further their communication skills, as opposed to speaking with patients, clients, or supervisors in community service or scholarly projects.

We postulate that it may be more effective to teach intrinsic CanMEDS roles through experiences such as community service learning and scholarly projects rather than traditional methods. Communication, collaboration, management, health advocacy, professionalism, and scholarly roles may not be successfully imparted passively in the classroom, but may need to be actively gained from real-world experiences. Again, this is in line with current research into the topic, as a recent systematic review has noted that community based service learning or participatory research has become increasingly utilized in medical education to teach complex abstract concepts such as social accountability and the knowledge, skills, and abilities needed to fulfill a physician's roles [19]. Additionally, medical students who took part in community-based research projects showed enhanced development of intrinsic roles and gained opportunities for professional growth outside the confines of traditional lecture-based courses [20].

\section{Understanding of medical research and academic output}

Our hypothesis that SDPO students will be associated with greater research aptitudes was consistent with the participants' responses. This is in line with current medical education ideology, as many medical schools either mandate scholarly projects as part of the curriculum or have supportive programs for student involvement in research in order to achieve these learning outcomes.

As anticipated, students in both CSLO and SDPO streams had higher rates of academic output than students in the DGO stream, which is likely attributed to increased involvement in and ownership of student-driven projects. Several studies have noted that opportunities for research as undergraduate or medical students would increase the likelihood of future involvement in clinical research [21-23]. However, the students who participated in our study reported being neutral about conducting future research. This may be a result of poor experiences or lack of opportunities to present or publish their projects. Perhaps providing students the opportunity to disseminate their findings, such as in a course-specific research conference, may allow more students to gain closure with their projects. 


\section{Impact on career trajectory}

Students in all three options disagreed that their work in DPAS 420 played a role in their choice of career or specialty, contrary to what is supported by current literature. A previous study of community service learning wherein first year medical students were placed in clinical settings with underserved populations showed that more than $90 \%$ believed that the program affected their career choice [24]. Additionally, much effort has been made to provide medical students with community service experience in rural communities in hopes of affecting students' choices in residency [25-27]. Furthermore, previous studies have also found that partaking in scholarly projects increased students' interest in pursuing academic medicine $[23,28]$. It is possible that the difference in findings is due to the amount of time allotted; students in DPAS 420 spend only 1.5 hours per week in the activity of their choosing. The options may have made a larger impact on students' career trajectories if they were pursued on a full-time basis.

\section{Perceived value of DPAS 420}

DGO students may not have viewed their learning option as an important experience because they did not have the chance to engage in non-traditional ways of learning that the CSLO and SDPO students were afforded. Additionally, these students may report less satisfaction as they did not actively choose to participate in DGO, but rather were compelled to take part in this option if they did not apply to the other options or were unsuccessful in their applications.

On the other hand, CSLO and SDPO students were able to engage in community service and scholarly projects that facilitated student development of intrinsic CanMEDS roles, improved research aptitude, and allowed for academic output. Our findings are in line with previous research in this area. Other studies have shown that students have enjoyed community service learning experiences and found them to be worthwhile endeavors $[17,24]$. Participation in scholarly projects by medical students has also been found to be enjoyable and worthwhile experiences, and also boosted their residency applications $[20,23]$.

\section{LIMITATIONS}

We recognize that there are some limitations to our study. First, a new instrument was utilized to collect data from participants, which had not been previously validated. Using a validated tool would have been preferred and as such, a literature search had been performed which generated one validated scale to assess social accountability. Unfortunately, some of the questions within that instrument pertained to the private healthcare system and could not be applied to Canadian healthcare. Specific steps were taken in developing the new questionnaire to improve its validity, including consultation with an expert panel consisting of professors and course directors in several Canadian medical schools and administering a pilot to medical students to gather feedback.

Second, our overall response rate was $16 \%$. This may make it more difficult to generalize our findings to the population at large as it may not be fully representative. However, the response rate may have been limited by our ability to reach all eligible participants. Residents may opt out of the class mailing list upon graduation or no longer access it, and would thus be unable to be reached. As such, the actual number of residents reached is not known, and thus the participation rate is in fact higher than that calculated based on this unknown denominator. Overall, our study had participation from both medical students and residents, from both genders, and from all four distributed sites. Furthermore, the medical student response rate is in line with other studies involving medical professionals $[29,30]$.

Third, we recognize that there may be a self-selection bias based on the learning options, as students were able to choose the option to which they applied. Moreover, students who did not apply to SDPO or CSLO were passively assigned to DGO. Table 1 demonstrates that the response rate for DGO students was slightly lower at $12 \%$ (compared to $19 \%$ for CSLO and $18 \%$ for SDPO); however, there were a similar number of total participants from each learning option. We recognize that students who chose SDPO may inherently have more research aptitude, and students who chose CSLO stream may be more socially accountable. However, we attempted to account for this through appropriate wording of the survey questions, specifically asking participants to assess only the impact of DPAS 420 on the outcomes measured. Furthermore, we believe that the opportunity for self-determination is an essential component of DPAS 420 that promotes autonomous motivation and personal satisfaction.

Lastly, the data collected for this study is self-reported, and thus may be subject to bias. However, it is important to measure subjective outcomes such as perceived understanding, confidence, importance, and satisfaction, as these are important outcomes in medical education. Furthermore, social accountability is defined by attitudes and behaviours, and there must be a component of self-reporting to determine an individual's attitudes. Therefore, we believe that these self-reported subjective outcomes are valid and worthwhile.

\section{CONCLUSION}

Medical students involved in different learning options in their population health course self-reported differing learning out- 
comes. This study demonstrated that students who participated in community-based or project-based learning reported significantly better acquisition of social accountability and intrinsic CanMEDS roles as compared to students who engaged in small group discussion. In addition, they also reported greater academic output and satisfaction with their educational experience. We suggest that complex abstract concepts, such as social accountability and intrinsic CanMEDS roles, may not be able to be taught passively in the classroom but may instead need to be gained from real world experiences. Therefore, it is imperative for medical schools to provide opportunities for students to participate in such endeavours throughout their medical training to foster the development of social accountability and CanMEDS roles.

\section{REFERENCES}

1. Dharamsi S, Espinoza N, Cramer C, et al. Nurturing social responsibility through community service-learning: Lessons learned from a pilot project. Med Teach. 2010;32(11):905-11.

2. Medical Council of Canada. Objectives for the qualifying examination [Internet]. 2015 [cited 2015 Mar 23]. Available from: http://apps.mcc.ca/Objectives_Online/objectives.pl?loc=home\&lang=english.

3. Royal College of Physicians and Surgeons of Canada. The CanMEDS Framework [Internet]. 2005 [cited 2015 Mar 23]. Available from: http://www.royalcollege.ca/portal/page/portal/rc/canmeds/framework.

4. Kharb P, Samanta PP, Jindal M, et al. The learning styles and the preferred teaching-learning strategies of first year medical students. J Clin Diagn Res. 2013;7(6):1089-92.

5. Kusurkar R, Croiset G. Autonomy support for autonomous motivation in medical education. Med Educ Online. 2015;20:27951.

6. Ten Cate T, Kusurkar R, Williams G. How self-determination theory can assist our understanding of the teaching and learning processes in medical education. Med Teach. 2011;33(12):961-73.

7. Williams G, Saizow R, Ryan R. The importance of self-determination theory for medical education. Acad Med. 1999;74(9):992-5.

8. Crabtree A, Mercer G, Horan R, et al. A qualitative study of the perceived effects of blue lights in washrooms on people who use injection drugs. Harm Reduct J. 2013;10(1):22.

9. Boelen C, Heck J. Defining and Measuring the Social Accountability of Medical Schools [Internet]. 1995 [cited 2015 Mar 23]. Available from: http:// apps.who.int/iris/bitstream/10665/59441/1/WHO_HRH_95.7.pdf?ua=1.

10. The University of British Columbia. Doctor, Patient, \& Society Community Advisory Board [Internet]. 2015 [cited 2015 Mar 23]. Available from: http:// sace.med.ubc.ca/education/dpas-cab/.

11. Leinster S. Evaluation and assessment of social accountability in medical schools. Med Teach. 2011;33(8):673-6.

12. Cohen JJ. Professionalism in medical education, an American perspective: From evidence to accountability. Med Educ. 2006;40(7):607-17.

13. Royal College of Physicians and Surgeons of Canada. CanMEDS 2015: Understanding the realities of today's physician [Internet]. 2015 [cited 2015 Mar 23]. Available from: http://www.royalcollege.ca/portal/page/portal/ $\mathrm{rc} / \mathrm{canmeds} /$ canmeds2015.

14. Crandall SJ, Volk RJ, Loemker V. Medical students' attitudes toward providing care for the underserved. Are we training socially responsible physicians? JAMA. 1993;269(19):2519-23.

15. Santina M, Perez J. Health professionals' sex and attitudes of health science students to health claims. Med Educ. 2003;37(6):509-13.

16. Hren D, Lukic IK, Marusic A, et al. Teaching research methodology in medical schools: Students' attitudes towards and knowledge about science. Med Educ. 2004;38(1):81-6.

17. O'Toole TP, Kathuria N, Mishra M, et al. Teaching professionalism within a community context: Perspectives from a national demonstration project. Acad Med. 2005;80(4):339-43.

18. Hojat $\mathrm{M}$, Mangione $\mathrm{S}, \mathrm{Nasca} \mathrm{TJ}$, et al. An empirical study of decline in empathy in medical school. Med Educ. 2005;38(9):934-41.

19. Hunt JB, Bonham C, Jones L. Understanding the goals of service learning and community-based medical education: A systematic review. Acad Med. 2011;86(2):246-51.

20. Fernando E, Jusko-Friedman A, Catton P, et al. Celebrating 10 years of undergraduate medical education: A student-centered evaluation of the Princess Margaret Cancer Centre-Determinants of Community Health year 2 program. J Cancer Educ. 2014;30(2):225-30.

21. Lloyd T, Phillips BR, Aber RC. Factors that influence doctors' participation in clinical research. Med Educ. 2004;38(8):848-51.

22. Solomon SS, Tom SC, Pichert J, et al. Impact of medical student research in the development of physician-scientists. J Investig Med. 2003;51(3):149-56.

23. Zier K, Friedman E, Smith L. Supportive programs increase medical students' research interest and productivity. J Investig Med. 2006;54(4):201-7.

24. Davidson RA. Community-based education and problem solving: The community health scholars program at the University of Florida. Teach Learn Med. 2002;14(3):178-81.

25. Ryser L, Crain J, Curry R, et al. The Northern Medical Program - Preliminary impacts on the physician community in Prince George [Internet]. 2008 [cited 2015 Mar 23]. Available from: http://www.unbc.ca/assets/community_development_institute/research/microsoft_word_nmp_final_report_ final.pdf.

26. Stearns JA, Stearns MA, Glasser M, et al. 2000. Illinois RMED: A comprehensive program to improve the supply of rural family physicians. Fam Med. 2000;32(1):17-21.

27. Wolff M, Young S, Maurana C. A senior elective: Promoting health in underserved communities. Fam Med. 2001;33(10):732-33.

28. Junge B, Quinones C, Kakietek J, et al. Promoting undergraduate interest, preparedness, and professional pursuit in the sciences: An outcomes evaluation of the SURE program at Emory University. CBE Life Sci Educ. 2010;9(2):119-32.

29. Buxton JA, McIntyre CC, Tu AW, et al. Who knows more about immunization: A survey of public health nurses and physicians? Can Fam Physician. 2013;59(11):e514-21

30. Pielak KL, McIntyre CC, Tu AW, et al. Identifying attitudes, beliefs and reported practices of nurses and doctors as immunization providers. J Adv Nurs. 2010;66(7):1602-11. 